\title{
UPAYA PENINGKATAN POLA HIDUP BERSIH SEHAT DI DESA IBUS MELALUI DISEMINASI TEKNOLOGI TEPAT GUNA FILTER AIR, CUCI TANGAN DIGITAL DAN MESIN PEMBUAT SABUN UNTUK MENGHADAPI PANDEMI COVID-19
}

\author{
Mukti Hamjah Harahap ${ }^{1}$, Hesti Fibriasari ${ }^{2}$, Miftahul Ihsan ${ }^{3}$, Irfandi ${ }^{4}$, Deo Demonta \\ Panggabean $^{5}$, Dedy Husrizal Syah ${ }^{6 *}$ \\ 1,4,5 Jurusan Fisika, Fakultas MIPA, Universitas Negeri Medan, Medan, Indonesia \\ ${ }^{2}$ Jurusan Bahasa Perancis, Fakultas Bahasa dan Seni, Universitas Negeri Medan, Medan, Indonesia \\ ${ }^{3} J u r u s a n$ Ilmu Keolahragaan, Fakultas Ilmu Keolahragaan, Universitas Negeri Medan, Medan, Indonesia \\ ${ }^{6} J u r u s a n$ Bisnis, Fakultas Ekonomi, Universitas Negeri Medan, Medan, Indonesia \\ * Penulis Korespodensi : dedy@unimed.in
}

\begin{abstract}
Abstrak
Pola hidup bersih dan sehat merupakan program yang telah lama dicanangkan oleh pemerintah melalui kementrian kesehatan. Berbagai upaya telah dilakukan oleh pemerintah akan tetapi belum menyentuh seluruh lapisan masyarakat. Program ini sangat relepan untuk menghadapi pandemi covid-19 yang sedang melanda dunia. Melalui program Diseminasi Teknologi Filter Air, Cuci Tangan Digital dan Mesin Pembuatan Sabun diharapkan dapat meningkatan pola hidup besih dan sehat di Desa Ibus, Kabupaten Serdang Bedagai. Metode yang dilakukan adalah pelatihan penggunaan dan perawatan alat yang di Diseminasikan kepada masyarakat serta penyuluhan perlunya pola hidup besih sehat untuk menghadapi pandemi Covid-19. Setelah dilakukan pelatihan dan penyuluhan selama periode satu bulan maka dilakukan pengukuran dampak dari program Diseminasi ditengah masyarakat. Dampak dari kegiatan ini ada dua hal yaitu dampak peningkatan kesadaran masyarakat akan pola hidup bersih sehat hususnya menggunakan air bersih, mencuci tangan dengan sabun serta dampak peningkatan ekonomi masyarakat. Dengan demikian dapat disimpulkan bahwa bahwa kegiatan ini sangat baik dilakukan dan disarankan kesinambungan program melalui perangkat yang ada ditengah masyarakat.
\end{abstract}

Kata kunci: desiminasi, PHBS, Covid-19

\begin{abstract}
A clean and healthy living behavior is a program that has long been launched by the government through the ministry of health. Some efforts had been done by the government but it has not touched to all levels of society. This program is very relevant to deal with the Covid-19 pandemic that is currently hitting this world. Through the Water Filter Technology Dissemination, Digital Hand Washing and Machine of Soap Making program, hopefully it can improve a clean and healthy living behavior in Ibus Village, Serdang Bedagai Regency. The method used is training on the use and maintenance of tools that are disseminated to the public and the counseling on the need for a clean and healthy lifestyle in facing the Covid-19 pandemic. After doing a training and counselling for a month, the impact of the Dissemination program is measured in the community. There are two things that can be obtained from the impact of this activity, firstly the impact of increasing public awareness for a clean and healthy lifestyle, especially in using clean water, washing hands with soap and then the impact of increasing the community's economy. Thus it can be concluded that this activity is very well to carry out and it is advisable to continue the government program through existing instruments in the community.
\end{abstract}

Keywords: desimination, clean and health living behavior, covid 19 


\section{PENDAhuluaN}

Desa Ibus lingkungan satu di Kabupaten Serdang Bedagai mayoritas penduduknya bersuku Jawa dengan pekerjaan petani sawah. Desa ini belum mendapatkan pasilitas air bersih sehingga masyarakat seluruhnya menggunakan air sumur untuk kebutuhan hidup seharihari. Kondisi lingkungan yang dikelilingi oleh persawahan membuat air tanah sangat mudah didapatkan. Akan tetapi air tanah yang diperoleh masyarakat sangat memprihatinkan, kondisi air yang keruh, berbau dan mengandung logam berat juga berpelung masuknya sisa pertisida dan pupuk yang digunakan disawah memasuki sumur masyarakat. Pada program ini melibatkan dua mitra dimana permasalahan yang paling mendasar pada mitra pertama adalah kurangnya pemahaman masyarakat tentang perilaku hidup bersih sehat dalam upaya pencegahan Covid-19 selama pandemi, hal ini dapat terlihat dengan berlangsungnya aktivitas mitra dimasjid untuk melakukan kegiatan keagamaan tanpa memperhatikan protokol kesehatan. Pengabaian jaga jaraj, tanpa menggunakan masker, tidak mencuci tangan dengan menggunakan sabun serta penggunaan air yang tidak bersih.

Sedangkan mitra yang kedua merupakan kelompok masyarakat yang berusaha membuat sabun batangan dari limbah minyak goreng dan pembuatan sabun cair dengan memakai berbagai bahan kimia serta air sumur yang kurang baik. Disamping itu permasalahan lainnya adalah manajemen pengelolaan yang belum dilakukan dengan baik termasuk mitra yang pertama. Kedua permasalahan mitra ini yang sesungguhnya berpotensi untuk menjadi pilar penggerak pola hidup sehat bersih perlu dilakukan pembinaan melalui program diseminasi teknologi dengan pola pelatihan, pendampingan serta penyuluhan sehingga dapat berperan dengan baik ditengah masyarakat.

Program diseminasi teknologi kepada masyarakat merupakan salah satu upaya yang dilakukan untuk mengatasi permasalahan mitra serta dapat meningkatakan potensi yang dimiliki oleh mitra. Potensi yang dimiliki oleh mitra akan mendorong masyarakat untuk melakukan pola hidup bersih sehat khususunya penggunaaan air bersih dengan diterapkannya alat pembersih air untuk kebutuhan masyarakat. Disamping itu itu juga disediakan alat cuci tangan digital sehingga masyarakat mencuci tanga tanpa harus menyentuh kran air maupun penggunaan sabun yang bergantian. Peralatan teknologi pembuatan sabun juga diharapakan dapat berperan dalam pengadaan sabun cair yang ekonomis ditengah masyarakat sehingga dapat terjangkau semua level ekonomi rumah tangga.

Penerapan tekonologi yang telah diberikan kepada masyarakat setelah melalui tahapan pelatihan, penyuluhan dan pendampingan diharapakan akan berdampak pada pemikiran dan kesadaran masyarakat untuk menerapkan pola hidup bersih sehat. Adapun dampak lainnya yang diharapkan dari program ini adalah peningkatan pengetahuan serta perekonomian masyarakat karena telah mendapatkan pemasukan pendapatan dari air bersih yang dikelola serta produksi sabun yang ekonomis.

\section{BAHAN DAN METODE}

Bahan dan alat yang gunakan pada kegiatan ini terdiri dari berbagai komponen utama diantaranya adalah : Bahan logam berupa besi plat dan besi padat sebagai bahan pembuatan sabun serta dinamo setengah PK sebagai penggerak. Bahan pembuatan mesin cuci tangan digital berupa akrilik, besi berongga dan komponen elektronika serta sensor infrared. Adapun bahan yang gunakan untuk pembuatan filter air siap minum terdiri dari tong plastik, pipa, mesin pompa, steling pengolahan air, filter bahan baku, filter bahan jadi, UV dan bahan lainnya.

Metode pelaksanaan kegiatan ini adalah dengan melakukan pelatihan penggunaan alat maupun perawatannya, pendampingan dan sosialisasi. Sebelum tahap pelatihan tim terlebih dahulu mengerjakan pelatan yang dibutuhkan dilaboratorium fisika dan bengkel yang melibatkan mahasiswa serta tim ahli lainnya. Setelah seluruh alat selesai dan telah di uji coba selama beberapa hari maka seluruh peralatan dibawak ke lokasi mitra. Setelah alat sampai dimitra maka alat tersebut diset sesuai dengan tempat yang disetujui mitra dan dihadiri oleh mitra. Mitra berperan aktif dalam pemasangan alat di lokasi. Setelah alat terpasang dengan baik, maka anggota mitra dilakukan pelatihan penggunaan alat dan perawatannya sampai dapat menguasai alat tersebut. Setelah mereka dapat menggunakan alat mereka didampingi untuk pengoperasian alat sehingga dapat berfungsi dengan baik. Proses berikutnya adalah penyuluhan kepada masyarakat dimana sebelumnya direncanakan melalui pertemuan langsung dengan mengumpulkan masyarakat akan tetapi rencana ini tidak dapat dilaksanakan karena kondisi pandemi Covid-19 sehingga dilakukan dengan menyebarkan stiker kepada masyarakat baik itu yang berukuran kecil maupun besar. Stiker yang besar ditempelnya ditempat yang sring dikunjungi masyarakat seperti masjid, warung kopi, kedai sampah dan tempat lainnya

\section{HASIL DAN PEMBAHASAN}

Kegiatan diseminasi teknologi kepada masyarakat dalam upaya peningkatan pola hidup bersih sehat di Desa Ibus Kabupaten Serdang Bedagai memberikan hasil sebagai luaran dibagi menjadi tiga yaitu:

a. Mesin cuci tangan digital.

Mesin pencuci tangan ini tanpa menyentuh kran baik sabun maupun airnya. Mesin ini menggunakan sensor inpra merah dengan jarak maksimum $35 \mathrm{Cm}$. Mesin ini dilengkapi dengan baterai $4500 \mathrm{mAh}$ sehingga dapat 
beroperasi dengan baik saat listrik PLN mati. Sedangkan desain kerangka meja berbahan besi dan sisinya berbahan akrilik sehingga lebih tahan terhadap air. Meja cuci tangan dirancang mobile sehingga mudah digunakan untuk tempat yang lain jika dibutuhkan.

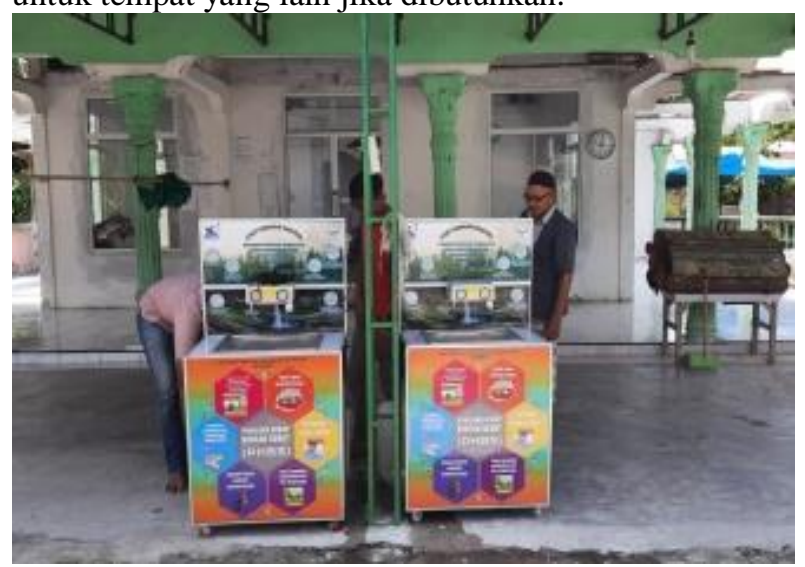

Gambar 1. Mesin cuci tangan digital

b. Mesin Mixer $1 / 2$ pk

Alat ini dirancang berkekuatan $1 / 2$ pk sesuai dengan kondisi mitra yang punya daya litrik hanya 900 watt. Mesin ini dapat diatur kecepatannya mulai dari nol hingga kecepatan maksimum dinamo sehingga dapat dengan mudah digunakan oleh mitra sesuai dengan kebutuhan mereka. Sedangkan daya tampung pengolahannya adalah 30 liter untuk satu kali pengolahan yang membutuhkan waktu sekitar 2 jam. Jika mitra ingin meningkatkan kapasitas produksinya, masih dapat diperbesar tabung pengolahannya dengan cara membuat tabung yang baru

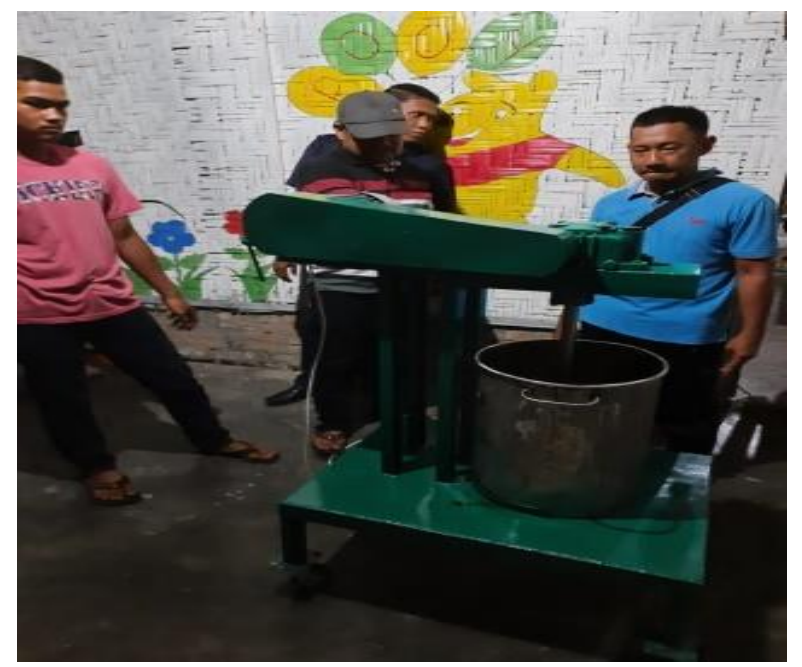

Gambar 2. Mesin mixer pembuatan sabun

c. Mesin Filter Air Siap Minum

Sistem filter air siap minum yang dirancang pada kegiatan ini mempunyai kapasitas produksi 140 galon per hari. Mesin ini dirancang dengan filter bertingkat yaitu filter air baku terdiri dari 2 tingkat dan filter air jadi terdiri dari 2 tingkat dan terahir lewat UV agar kuman dalam air mati. Hasil filtersasinya adalah RO plus bioenergi sehingga menghasilkan cita rasa air yang baik dan enak.

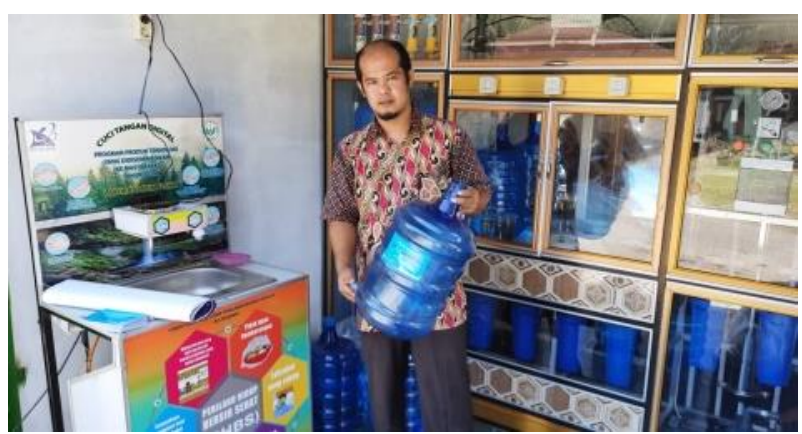

Gambar 3. Mesin filter air siap minum

Diseminasi teknologi kepada masyarakat Lingkungan satu, Desa Ibus, Kabuapaten Serdang Bedagai dengan menerapkan peralatan teknologi mesin cuci tangan digital, mesin pembuat sabun dan mesin filter air siap minum sebagai upaya pendukung peningkatan pola hidup bersih sehat telah dilaksanakan. Pelaksanaan kegiatan ini efektif mulai sejak bulan September, akan tetapi penggunaan alat ditengah masyarakat mulai Oktober. Berdasarkan pengamatan penggunaan alat selama satu bulan berjalan dengan baik dan mendapatkan apresiasi yang positif dari masyarakat. Hal ini dapat dilihat dari data yang telah diperoleh pada tabel berikut:

Tabel 1. Data pengamatan perubahan perilaku masyarakat sebelum dan sesudah penerapan teknologi

\begin{tabular}{llll}
\hline No & $\begin{array}{l}\text { Parameter } \\
\text { yang diamati }\end{array}$ & $\begin{array}{l}\text { Sebelum } \\
\text { penerapan } \\
\text { alat }\end{array}$ & $\begin{array}{l}\text { Setelah } \\
\text { penerapan } \\
\text { alat }\end{array}$ \\
\hline 1 & $\begin{array}{l}\text { Perilaku } \\
\text { mencuci tangan }\end{array}$ & $14 \%$ & $78 \%$ \\
2 & $\begin{array}{l}\text { Mencuci dengan } \\
\text { menggunakan } \\
\text { sabun }\end{array}$ & $67 \%$ & $96 \%$ \\
3 & $\begin{array}{l}\text { Penggunaan air } \\
\text { bersih untuk } \\
\text { konsumsi }\end{array}$ & $8 \%$ & $98 \%$ \\
\hline
\end{tabular}

Berdasarkan data diatas, terlihat peningkatan perilaku masyarakat setelah penerapan teknologi ditengah masyarakat dan adanya sosialisasi. Pada perilaku mencuci tangan peningkatan sangat singnipikan pada kalangan dewasa, sedangkan pada anak masih rendah disebabkan keterlibatan mereka pada kegiatan ini tidak ada, hanya dari masukan orang tua dan remaja 
masjid yang telah mengikuti program. Oleh karena itu masih dibutuhkan penyadaran bagi anak-anak dari pihak keluarga agar mereka dapat melaksanakan salah satu pola hidup bersih mencuci tangan.

Penggunaan sabun dalam mencuci juga mengalami perubahan yang sangat baik disebabkan oleh terjangkauanya sabun yang bersumber dari produksi mitra. Pola penukaran minyak jelanta dengan sabun cair juga sangat memotipasi masyarakat dalam penggunaan sabun dalam mencuci. Akan tetapi masih terdapat sedikit masyarakat yang belum menunjukkan perilakunya untuk menggunakan sabun setiap mencuci disebakan oleh kebiasaan yang sudah terjadi selama ini. Untuk itu gerakan penyadaran masyarakat terus dilakukan oleh kedua mitra sehingga pada saatnya seluruh elemen masyarakat menyadari akan perlunya mencuci menggunakan sabun.

Mengkonsumsi air bersih merupakan salah satu perilaku hidup bersih sehat yang sangat berpengaruh pada tingkat kesehatan masyarakat. Hal ini sangat dipengaruhi oleh ketersediaan air bersih layak minum ditengah masyarakat yang terjangkau. Disamping itu pola kebiasaan mengkonsumsi air tidak layak minum yang belum berdampak pada kesehatan mereka juga menjadi penghambat akan munculnya kesadaran mereka untuk menggunakan air bersih layak konsumsi. Oleh karena itu melalui kegiatan ini dilakukan sosialisasi untuk meningkatkan pengetahuan mereka serta menyediakan air layak konsumsi yang ekonomis. Dengan demikian dampak yang terlihat sangat baik dimana terjadi perubahan perilaku masyarakat. Keberhasilan ini didukung oleh ketersediaan air bersih yang ekonomis dan juga adanya program infak ke masjid Rp 1000 bagi setiap penggunaan satu galon air. Dengan kultur masyarakat yang religi sangat mendukung akan kesadaran mereka menggunakan air bersih layak konsumsi yang telah tersedia. Adapun kelompok masyarakat yang belum menggunakan air bersih adalah kelompok orang tua yang masih berpikiran bahwa air harus tetap dimasak dengan api, sehingga masih ditemukan yang belum menggunakan air bersih tersebut.

Perilaku hidup bersih sehat dilingkungan satu, Desa Ibus, Kabupaten Serdang Bedagai untuk tiga parameter yang ada sangat memberikan dampak yang positif bagi peningkatan pola hidup bersih sehat. Akan tetapi berbagai kendala yang masih dihadapi ditengah masyarakat masih membuthkan waktu untuk perubahannya. Untuk itu kedua mitra tetap berkomitmen untuk terus melakukan penyadaran bagi kelompok masyarakat yang belum nelakukan pogram yang telah berjalan. Keterlibatan seluruh elemen masyarakat dalam menjaga dan mensosialisasikan pola hidup bersih sehat secara berkesinambungan merupakan ujung tombak kesuksesan program ini. Kelompok Jemaah masjid yang terdiri dari orang tua dan remaja masjid yang telah berkomitmen keberlangsungan program memberikan harapan yang positif akan peningkatan kesadaran masyarakat. Demikian juga dengan kelompok penghasil sabun yang terus melakukan upaya yang baik untuk menyampaikan misi dari program ini.

\section{KESIMPULAN}

Upaya peningkatan pola hidup bersih sehat ditengah masyarakat melalui diseminasi teknologi mesin digital pencuci tangan, mesin pembuat sabun dan mesin filter air siap minum memberikan dampak yang positif bagi perubahan perilaku masyarakat. Dengan perubahan perilaku yang positif berkesinambungan diharap akan berdampak pada peningkatan kesehatan masyarakat sehingga dapat berkontribusi bagi kekuatan tubuh setiap individu masyarakat dalam menghadapi pandemic covid19 maupun penyakit lainnya.

\section{UCAPAN TERIMA KASIH}

Pada kesempatan ini kami tim pengabdi kepada masyarakat mengucapkan terima kasih dan penghargaan yang setinggi-tingginya kepada seluruh Pimpinan Universitas Negeri Medan yang telah memberikan dukungan dan arahan akan terlaksananya kegiatan ini, khususnya kepada Bapak Rektor Dr. Syamsul Gultom, M.Kes, dan juga ketua LPPM Bapak Prof. Dr. Baharuddin, MT serta seluruh staf yang terlibat. Penghargaan dan ucapan terima kasih kami sampaikan kepada Kementrian RistekBrin yang telah memberikan kesempatan, kepercayaan serta dukungan dana kepada kami sehingga kami tim pengabdi serta Unimed dapat berkontribusi kepada masyarakat dalam program Diseminasi teknologi pada tahun 2020. Semoga kegiatan ini dapat berjalan dengan baik dimasa yang akan datang dan kami civitas Unimed tetap dapat berkonstibusi di tengah masyarakat.

\section{DAFTAR PUSTAKA}

Agustina, Yulia Mega. 2013. Hubungan Antara Perilaku Hidup Bersih Dan Sehat (PHBS) Dengan Kejadian Diare Pada Balita Di Posyandu Dusun Ketangi Desa Banyusoco Kecamatan Playen Kabupaten Gunungkidul Yogyakarta. Yogyakarta: Sekolah Tinggi Ilmu Kesehatan 'Aisyiyah.

Clark, J., Henk, J. K., Crandall, P. G., Crandall, M. A., \& O'Bryan, C. A. (2016). An observational study of handwashing compliance in a child care facility. American Journal of Infection Control, 44(12), 1469-1474. https://doi.org/10.1016/j.ajic.2016.08.006

Departemen Kesehatan RI. 2013. Hasil riset kesehatan dasar Indonesia 2013.

GomoMJ,2013.Gambaran Perilaku Hidup Bersih dan Sehat (PHBS) Sekolah Pada Siswa Kelas Akselerasi di SMPN8 Manado Fak.Kedokteran 
UNRAT: Manado. Jurnale Biomedik (eBM) Vol.1/No.1/Maret2013. Hal503-505

Kuzik, N., Poitras, V. J., Tremblay, M. S., Lee, E.-Y., Hunter, S., \& Carson, V. (2017). Systematic review of the relationships between combinations of movement behaviours and health indicators in the early years (0-4 years). BMC Public Health, 17(S5), 849. https://doi.org/10.1186/s12889-017-4851-1

Masruroh, Azifa Tu. 2014. Hubungan Perilaku Hidup Bersih Dan Sehat (PHBS) Dengan Kejadian Skabies Pada Santriwati Pondok Pesantren Assalafiyyah Mlangi Nogotirto Sleman.
Yogyakarta: Sekolah Tinggi Ilmu Kesehatan 'Aisyiyah.

Safitri H I, Harun, Membiasakan pola hidup sehat dan bersih pada anak usia dini selama pandemi covid-19, Jurnal Obsesi, Vol 5 isue 1 tahun 2020, hal 385-394

Suyatmin, S., \& Sukardi, S. (2018). Development of Hygiene and Healthy Living Habits Learning Module for Early Childhood Education Teachers. Unnes Journal of Public Health, 7(2), 89-97.

https://doi.org/10.15294/ujph.v7i2.19470 